\title{
Basal Ganglia Output and Cognition: Evidence from Anatomical, Behavioral, and Clinical Studies
}

\author{
Frank A. Middleton \\ Research Service (151S), VA Medical Center, Syracuse, New York 13210 \\ and \\ Peter L. Strick
}

Research Service (151S), VA Medical Center, and Departments of Neurosurgery and Neuroscience/Physiology, State University of New York Health Science Center at Syracuse, Syracuse, New York 13210

\begin{abstract}
The traditional view that the basal ganglia are simply involved in the control of movement has been challenged in recent years. Three lines of evidence indicate that the basal ganglia also are involved in nonmotor operations. First, the results of anatomical studies clearly indicate that the basal ganglia participate in multiple circuits or 'loops' with cognitive areas of the cerebral cortex. Second, the activity of neurons within selected portions of the basal ganglia is more related to cognitive or sensory operations than to motor functions. Finally, in some instances basal ganglia lesions cause primarily cognitive or sensory disturbances without gross motor impairments. In this report, we briefly review some of these data and present a new anatomical framework for understanding the basal ganglia contributions to nonmotor function. (๑) 2000 Academic Press
\end{abstract}

\section{INTRODUCTION}

It has long been known that basal ganglia pathology is associated with more than simply motor deficits. For example, when Martin (1927) reviewed all known cases of hemiballismus and hemichorea resulting from damage to the subthalamic nucleus he concluded that ". . . in nearly every case there is a mental disturbance - at first chiefly an emotional change (excessive anxiety), and afterwards loss of memory, confusion, and disorientation." Similarly, Wilson (1912) noted in his classic analysis of progressive lenticular degeneration (i.e., Wilson's disease) that “ ‘. . some form of mental change

Address correspondence and reprint requests to Peter L. Strick, Research Service (151S), VA Medical Center, 800 Irving Ave., Syracuse, NY 13210. Fax: (315) 448-7606. E-mail: strickp@hscsyr.edu. 
or impairment is specifically referred to in at least eight of the twelve cases; its importance, therefore, must not be underestimated.' Despite these early observations, the motor functions of the basal ganglia have always received the greatest emphasis in both the clinical and scientific literature. It is only in the last 10-15 years that the possible involvement of the basal ganglia in higher mental function has been explored in any detail. This renewed interest in the nonmotor functions of the basal ganglia has been fueled in large part by significant advances in the fields of experimental neuroanatomy and neurophysiology. In this review, we discuss some of the recent evidence for basal ganglia involvement in higher cognitive function. In addition, we will provide support for our conclusion that multiple closed loops form the basic structural framework for basal ganglia interactions with diverse regions of the cerebral cortex, including regions outside the frontal lobe.

\section{ANATOMICAL STUDIES}

In general, the basal ganglia can be described as consisting of a group of "input structures" (the caudate, putamen, and ventral striatum) that receive direct input from the cerebral cortex and "output structures" (the internal segment of globus pallidus, substantia nigra pars reticulata, and ventral pallidum) that project back to the cerebral cortex via the thalamus. Thus, a major feature of basal ganglia anatomy is their participation in multiple "loops" with the cerebral cortex. The "classical" view of these loops was that they gathered information from widespread cortical areas. This information was then "funneled"' through basal ganglia circuits, where it ultimately converged on output nuclei that innervate the ventrolateral thalamus (for example, see Kemp \& Powell, 1971). The ventrolateral thalamus was thought to project to a single cortical area, the primary motor cortex (M1). Thus, basal ganglia loops were thought to function largely in the domain of motor control.

In 1986, Alexander, DeLong, and Strick reviewed the results of numerous anatomical studies and proposed that rather than serving solely as a site of anatomical convergence, the basal ganglia participated in five parallel loops with the cerebral cortex. One of these cortico-basal ganglionic circuits involved skeletomotor areas of the cortex and another was with oculomotor areas. The remaining three loops were with nonmotor areas in the frontal lobe. These nonmotor regions included the dorsolateral prefrontal cortex (area 46), the lateral orbitofrontal cortex (area 12), and the anterior cingulate/ medial orbitofrontal cortices (areas 24 and 13). These frontal regions are known to be involved in planning, working memory, rule-based learning, attention, and other aspects of higher executive function. Thus, according to Alexander et al. (1986) these circuits would enable the basal ganglia to influence a broad range of behavior.

Efforts to evaluate the circuitry proposed by Alexander et al. (1986) were 
faced with a number of technical limitations. Chief among these was the inability of most conventional anatomical techniques to trace multisynaptic connections in the brain. In recent years, this limitation has been overcome with the development of techniques for using neurotropic viruses as transneuronal tracers. This approach enables one to identify second- and in some instances third-order neurons that either receive input from or project to a specific area of cerebral cortex (Zemanick et al., 1991; Strick \& Card, 1992; Hoover \& Strick, 1999). We have used virus tracing to examine the structure of basal ganglia-thalamocortical pathways in monkeys (Hoover \& Strick, 1993, 1999; Lynch et al., 1994; Middleton \& Strick, 1994, 1996). Here we review our recent observations regarding the link between basal ganglia output and nonmotor areas of the cerebral cortex.

Our initial experiments on nonmotor areas of the cerebral cortex examined whether three regions of prefrontal cortex, areas 9, 12 and 46, are the target of output from the basal ganglia (Fig. 1). Then we examined whether a region of inferotemporal cortex, area TE, is the target of basal ganglia output. Each of these cortical areas is known to project to the input structures of the basal ganglia. However, it has been unclear whether each of these cortical areas is a target of the output stage of basal ganglia processing. To address these questions, we injected the McIntyre-B strain of herpes simplex virus type 1 (HSV1) into areas 9, 12, 46, and TE in separate animals. The McIntyre-B strain is transported transneuronally in the retrograde direction. After cortical injections, the virus is initially transported in the retrograde direction to label all those "first-order"' neurons in the thalamus that innervate the injection site. Then the virus is transported transneuronally in the retrograde direction to label "second-order" neurons at subcortical sites that project to the labeled first-order neurons in the thalamus (Figs. 2 and 3).

We found that each of the cortical areas we examined was a target of basal ganglia output. Some cortical areas (9m and 9l) received input from both the internal segment of globus pallidus (GPi) and the substantia nigra pars reticulata (SNpr). Other areas received input from either GPi (46d) or SNpr $(46 \mathrm{v}, 12 \mathrm{l}$, and TE). The spatial distribution of labeled neurons within the GPi and SNpr depended on the location of the cortical injection site. GPi neurons labeled by area 9 injections were always located dorsal to those labeled by area 46 injections (Fig. 2). Similarly, SNpr neurons labeled by area 9 injections were located rostral to those labeled by injections of other cortical areas. In caudal regions of SNpr, the neurons labeled by area 12 injections were found medial to those labeled by area 46 and area TE injections (Fig. 3), and the neurons labeled by area TE injections were found dorsal to those labeled by area 46 injections (not shown). Shifts in the location of labeled neurons were observed even following injections into portions of single cortical areas (e.g., Fig. 3, areas 9m and 91). Thus, each of the nonmotor areas we examined appeared to be the target of topographically organized output from the basal ganglia. 


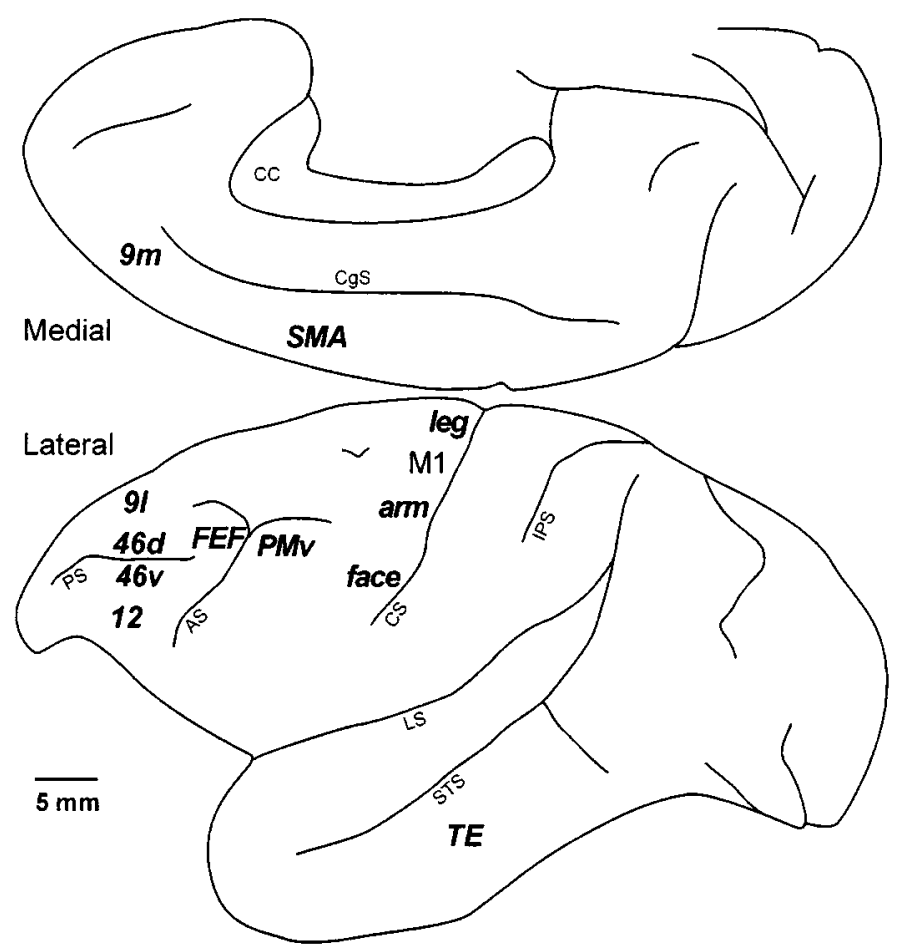

FIG. 1. Cortical targets of basal ganglia output. Areas labeled in bold represent cortical regions that were injected with the McIntyre-B strain of HSV1. Retrograde transneuronal transport of the virus labeled neurons in GPi or SNpr. AS, arcuate sulcus; CC, corpus callosum; $\mathrm{CgS}$, cingulate sulcus; CS, central sulcus; FEF, frontal eye field; IPS, intraparietal sulcus; LS, lateral sulcus; M1, primary motor cortex; PMv, ventral premotor area; PS, principal sulcus; SMA, supplementary motor area; STS, superior temporal sulcus; TE, area of inferotemporal cortex.

In other studies, we examined the origin of basal ganglia output to skeletomotor and oculomotor areas of the cerebral cortex (Hoover \& Strick, 1993, 1999; Lynch et al., 1994). Injections of the McIntyre-B strain of HSV1 were made into the primary motor cortex (M1), supplementary motor area (SMA), ventral premotor area $(\mathrm{PMv})$, and frontal eye field (FEF). We found that each of these cortical areas is the target of basal ganglia output. Importantly, the regions of GPi and SNpr that were labeled after injections into the different motor areas were separate from each other and from the regions labeled after injections into the nonmotor areas described above (Figs. 2 and 3). Thus, the basal ganglia-thalamocortical system is characterized by multiple parallel pathways to motor and nonmotor areas of the cerebral cortex (Fig. 4).

Up to this point, we have examined a relatively small set of the potential targets of basal ganglia output. Thus, the full extent of basal ganglia influence 

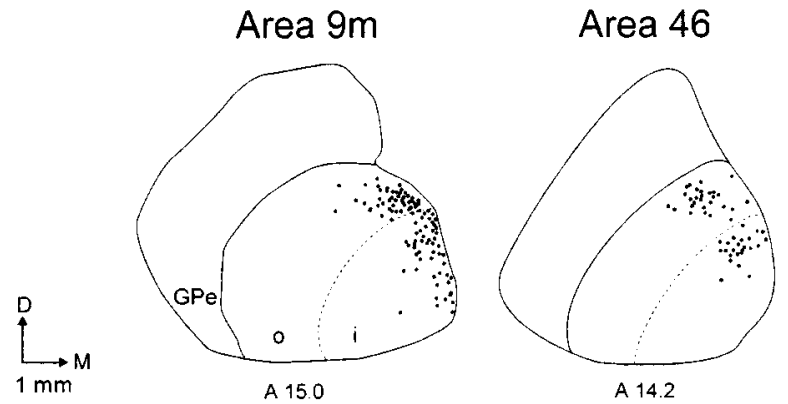

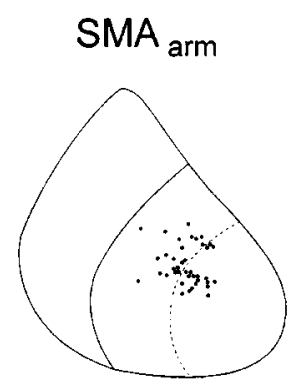

A 13.7

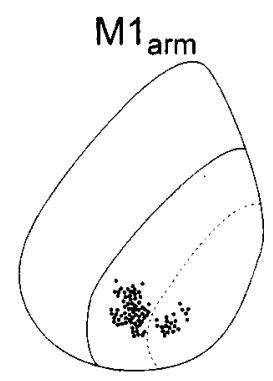

A 14.0

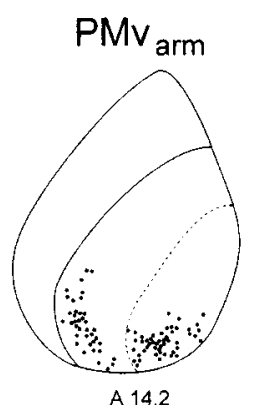

A 14.2

FIG. 2. Pallidal projections to motor and nonmotor cortical areas. Injections of HSV1 into portions of M1, PMv, SMA, and areas 46 and 9 all labeled neurons in GPi. Representative coronal sections through the globus pallidus of animals that received these injections are shown. The sections display labeled neurons found on one to three adjacent sections. GPe, external segment of globus pallidus; o, outer portion of the internal segment of globus pallidus; $\mathrm{i}$, inner portion of the internal segment of globus pallidus.

on the cerebral cortex remains to be determined. However, these results indicate that, overall, basal ganglia output has the capacity to influence a broad range of motor and nonmotor behavior. On the other hand, when each "output channel"' is considered individually, it appears to be concerned with a specific aspect of motor or nonmotor function. A review of the pattern of inputs to each output channel in the basal ganglia suggests that the cortical area that is the target of output from a channel also is the major cortical input to that channel (Strick et al., 1995). This suggests that multiple closed loops form the major structural framework that links the cerebral cortex with the basal ganglia.

\section{PHYSIOLOGICAL STUDIES}

It should be clear from the material presented above that a substantial component of the output from the basal ganglia is directed to nonmotor areas of the cerebral cortex. However, these data do not indicate the nature of the information transmitted to cortex by this component of basal ganglia output. 


\section{Rostral Nigra}
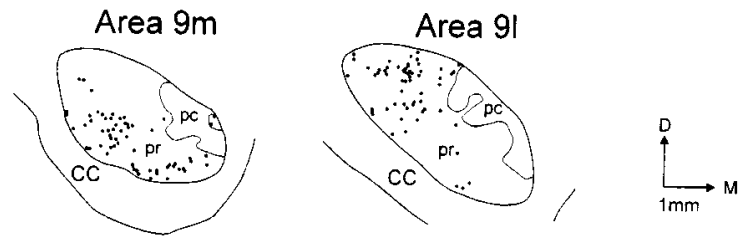

\section{Caudal Nigra}
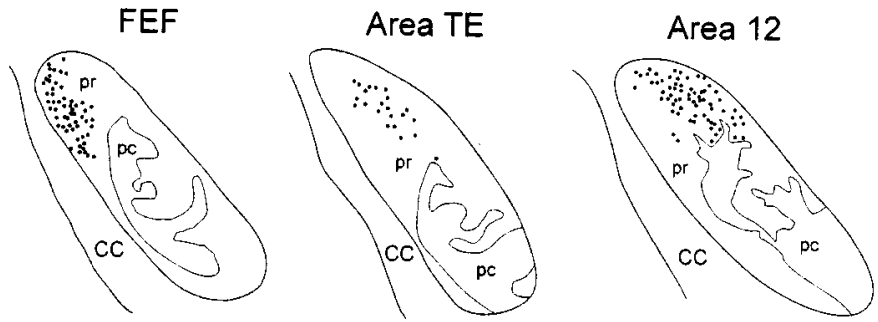

FIG. 3. Nigral projections to motor and nonmotor cortical areas. Injections of HSV1 into portions of area 9, area 12, the FEF, and area TE all labeled neurons in SNpr. The conventions for this figure are the same as those for Fig. 2. CC, crus cerebri; pc, pars compacta; pr, pars reticulata.
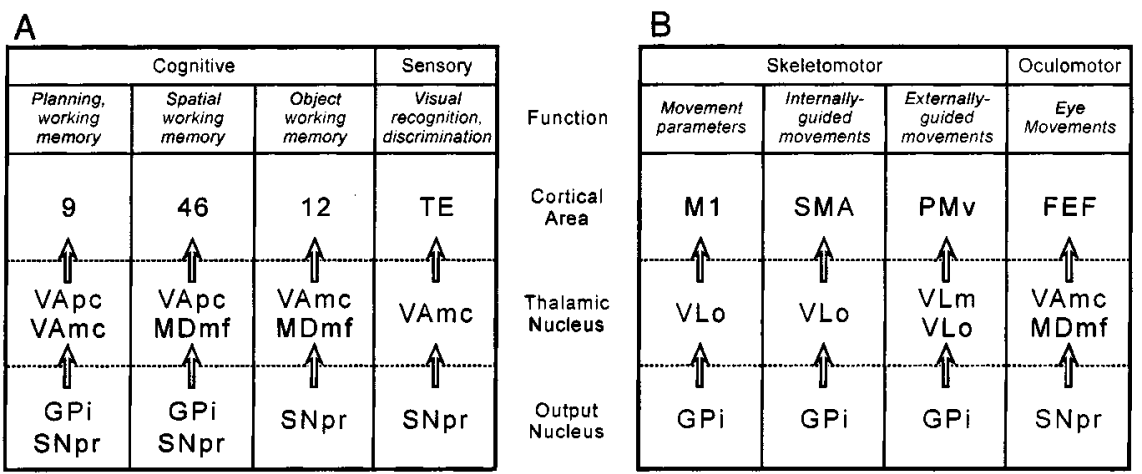

FIG. 4. Nonmotor (A) and motor (B) output channels. The basal ganglia project to a diverse set of cortical areas via the thalamus. These projections form anatomically and functionally distinct output channels. Thalamic abbreviations according to Olszewski (1952). 
In this section, we review the recent evidence that basal ganglia outputs to nonmotor areas of cortex are involved in nonmotor function.

\section{Single-Unit Recording}

Numerous single-unit recording studies have been carried out on the output nuclei of the primate basal ganglia. These studies indicate that only specific regions of the GPi and SNpr contain neurons whose activity is related to skeletomotor or oculomotor commands (e.g., DeLong, 1971; Hikosaka \& Wurtz, 1983; DeLong et al., 1983; Anderson \& Horak, 1985; Schultz, 1986; Mink \& Thach, 1991; Hikosaka et al., 1993; Mushiake and Strick, 1995a,b). In addition, extensive physiological mapping of the GPi is routinely performed in patients undergoing pallidotomy for the treatment of Parkinson's disease (e.g., Bakay et al., 1992; Baron et al., 1996). The regions of the GPi and SNpr that contain "motor-related" neurons in these studies appear to coincide with the portions of the nuclei that target motor areas of the cerebral cortex (Hoover \& Strick, 1993, 1999; Lynch et al., 1994; Strick et al., 1995). In contrast, large portions of GPi and SNpr contain neurons whose activity is not modulated by simple skeletomotor or oculomotor tasks. Many of these " "nonmotor' neurons appear to be located within regions of GPi and SNpr that target prefrontal and inferotemporal areas of cortex. Other neurons with nonmotor responses fall within basal ganglia regions whose cortical targets have yet to be identified.

Recordings of single neurons in trained laboratory primates have provided direct evidence that basal ganglia output channels to nonmotor areas of the cerebral cortex could be involved in cognitive or higher order visual function. Hikosaka and colleagues (Hikosaka \& Wurtz, 1983; Hikosaka et al., 1993) recorded the activity of neurons in the SNpr of monkeys trained to perform tasks that required them to make saccadic eye movements to the remembered location of a visual target. Some neurons in the SNpr showed activity that changed during the "cue" and "delay" periods of the tasks, but not during the "movement" period. Interestingly, the locations of some of these cueand delay-related neurons appear to correspond to the portions of the SNpr that we have shown project to prefrontal and inferotemporal cortex. Cueand delay-related neurons were frequently found in physiological studies of prefrontal and inferotemporal areas of cortex (Fuster \& Alexander, 1971; Kubota \& Niki, 1971; Gross, 1972; Niki \& Watanabe, 1976; Fuster et al., 1982; Goldman-Rakic, 1987, 1990; Tanaka et al., 1991; Miyashita, 1993; Funahashi et al., 1989, 1997; Fuster, 1997). Thus, the properties of neurons in nigral output channels that target prefrontal and inferotemporal cortex are in many respects similar to those of neurons in the cortical areas they innervate.

Similarly, Mushiake and Strick (1995a,b) obtained evidence for the involvement of pallidal output channels in the cognitive operations necessary 
for the performance of remembered sequences of pointing movements. They trained monkeys to perform sequential pointing movements under two task conditions (for a more detailed description of the task and training, see Mushiake \& Strick, 1993). In both conditions, the monkey faced a panel with five touch pads which were numbered 1 to 5 (left to right). A small red light emitting diode (LED) was located over each touch pad. The monkey began a trial by placing his right hand on a hold key in front of him for a variable "Hold" period. In one condition, termed the Remembered Sequence Task (REM task), LEDs over three touch pads were illuminated in a sequence as an instruction to the monkey. At the end of a variable "Instructed Delay" period, an auditory "Go" signal told the monkey to release the hold key and press the three touch pads according to the instructed sequence (i.e., in the same order that the LEDs were illuminated). Thus, the specific sequence of movements that the monkey performed during each trial of the REM task was initially stored in "working memory" and then internally guided.

Approximately $15 \%$ of the task-related neurons in the globus pallidus were "instruction-related" (I-related), that is, they displayed changes in activity during the Instructed Delay period. Some of these I-related neurons displayed transient changes in activity immediately after the presentation of visual cues ("Cue" neurons). Other I-related neurons displayed changes in activity only during the delay period following the illumination of the three instruction LEDs ("Delay" neurons). Some of the I-related activity was specific for the particular remembered sequence of movements that the animal was preparing to perform. Still other I-related neurons displayed changes in activity during both task periods ("Cue + Delay" neurons).

The I-related activity in the globus pallidus is similar to activity found in prefrontal cortex during instructed delay periods (Fuster \& Alexander, 1971; Kubota \& Niki, 1971; Niki \& Watanabe, 1976; Fuster et al., 1982; Funahashi et al., 1989, 1997; Fuster, 1997). In fact, one study reported instructionrelated activity in prefrontal cortex using a sequential movement task very similar to the one used for analysis of activity in GPi (Funahashi et al., 1997). I-related neurons tended to be located in dorsomedial regions of the globus pallidus. This suggests that they are within output channels that innervate motor areas concerned with motor preparation (e.g., the supplementary motor area and presupplementary motor area) and/or within channels that innervate prefrontal areas involved in working memory (areas 46 and 9). Thus, pallidal activity during instructed delay periods could participate in higher order motor and/or cognitive functions.

\section{Functional Imaging Studies in Humans}

There have been relatively few functional imaging studies of activation in the output nuclei of the basal ganglia during cognitive tasks. This is due, at least in part, to the fact that the small sizes of the GPi and SNpr, and their 
location deep within the brain, present substantial technical barriers for most imaging techniques. However, we would like to highlight two studies of GPi activation.

Owen and colleagues $(1997,1998)$ used positron emission tomography (PET) to compare the activity in GPi of normal subjects and patients with Parkinson's disease during the performance of three different tasks: a difficult planning task (the Tower of London task), a spatial working memory task, and simple visually guided movements. The planning and spatial working memory tasks had been shown in prior studies from this group to be associated with strong activation of areas 9 and 46 in normal subjects (Owen et al., 1996; see also Baker et al., 1996). In normal subjects, GPi displayed striking activation during the planning and spatial working memory tasks. In contrast, similar activations of GPi were not present in the patient group. Since patients with Parkinson's disease were previously shown to be impaired in the performance of the planning and spatial working memory tasks (Owen et al., 1992, 1993), the authors concluded that GPi outputs to dorsolateral prefrontal cortex (areas 9 and 46) play an important role in the normal performance of these tasks.

In another PET study, Jueptner and colleagues (1997a,b) asked normal subjects to learn sequences of eight finger movements (key presses). They then compared the brain activity during learning of new sequences with that seen during performance of previously learned sequences. An examination of their data shows that rostrodorsal portions of the globus pallidus as well as portions of areas 9 and 46, the dorsolateral caudate, and the ventroanterior nucleus of the thalamus displayed increased activation preferentially during the learning of new sequences. All of these structures participate in basal ganglia loops with areas 9 and 46 . Thus, learning or planning a long sequence of actions appears to involve basal ganglia loops with dorsolateral prefrontal cortex.

\section{CLINICAL AND PATHOLOGICAL STUDIES}

Space does not permit us to provide a complete analysis of the cognitive disturbances produced by basal ganglia pathology. Several reviews have been published on this subject (e.g., Heindel et al., 1989; Laplane et al., 1989; Levin et al., 1989; Saint-Cyr et al., 1988; Taylor et al., 1990; Owen et al., 1992, 1993; Cummings, 1993; Farina et al., 1994; Partiot et al., 1996; Dubois \& Pillon, 1997). Instead we would like to emphasize how the arrangement of output channels in the basal ganglia may provide an anatomical framework for understanding the consequences of basal ganglia pathology.

From a global perspective, it has long been recognized that damage to the input stage of basal ganglia circuitry (i.e., the caudate and putamen) produces cognitive as well as motor symptoms. For example, Parkinson's disease begins with pathological changes that are predominately in sensorimotor por- 
tions of the striatum (e.g., mid putamen; see Kish et al., 1988) and is associated at its onset with largely motor symptoms. In contrast, Huntington's disease begins with pathological changes primarily in the associative portions of the striatum (e.g., anterior caudate; see vonSattel et al., 1985) and is associated at its onset with cognitive disturbances (reviewed in Lawrence et al., 1996). The sensorimotor and associative regions of the striatum provide input to different portions of the output nuclei of the basal ganglia. Thus, differences in the symptoms of early Parkinson's and Huntington's diseases could be a reflection of abnormal activity in output channels to different cortical areas.

Observations from current animal models of Parkinson's and Huntington's diseases indicate that it is possible to dissociate cognitive and motor impairments. Primates given chronic low doses of MPTP (to mimic Parkinson's disease) or 3-NP (to mimic Huntington's disease) display profound cognitive and visual deficits prior to the development of gross motor impairments (see Schneider \& Roeltgen, 1993; Roeltgen \& Schneider, 1994; Schneider \& Pope-Coleman, 1995; Palfi et al., 1996). These results, along with those from selective lesions of the sensorimotor and associative portions of the primate striatum (e.g., Divac et al., 1967; Miyachi et al., 1997), support the concept that basal ganglia systems contain separate motor and cognitive circuits.

There is also growing evidence that pathology limited to the output nuclei of the basal ganglia results not only in motor disorders, but also in cognitive and sensory dysfunction. For example, a careful analysis of the effects of ventral pallidotomy for the treatment of Parkinson's disease concluded that this surgical procedure can cause cognitive impairments (Trepanier et al., 1998). The anatomy described above provides a simple explanation for these effects. Pallidotomy is intended to interrupt abnormal signals in motor circuits through the basal ganglia by destroying output channels in GPi that innervate motor areas of the cerebral cortex. To be effective the pallidal lesions must be large. Thus, it is likely that the cognitive deficits result from extension of the lesion into adjacent pallidal output channels that innervate prefrontal cortex.

Lesions localized to SNpr also appear to produce alterations in motor and nonmotor behavior. Perhaps the best illustration of this was a report of a patient with a bilateral stroke involving a portion of SNpr (McKee et al., 1990). This patient demonstrated profound deficits in working memory, visual hallucinations, and mild neurological symptoms, including oculomotor abnormalities. Our anatomical results show that the SNpr contains channels directed at oculomotor, prefrontal, and inferotemporal areas of cerebral cortex (Figs. 3 and 4). All of these output channels are packed into a relatively small area. It is possible that interruption of the output channels to prefrontal cortex could have led to the working memory deficits that this patient exhibited, while interruption of the channels to the FEF could have produced his oculomotor difficulties. We have previously argued that alterations in the 
nigral channels to inferotemporal cortex could have caused this patient's visual hallucinations (Middleton \& Strick, 1996). Thus, the anatomical arrangement of output channels in SNpr provides a simple explanation for the remarkably diverse set of symptoms that can arise from nigral damage.

We are struck by the similarity between the class of symptoms displayed by the patient of McKee and colleagues (1990) and some of the cardinal symptoms of schizophrenia. There is growing evidence that unmedicated, first-episode schizophrenics display oculomotor abnormalities including deficits in smooth pursuit eye movements and saccadic dysmetria (reviewed in Hutton \& Kennard, 1998; Hutton et al., 1998). Patients with "negative symptom" schizophrenia also display cognitive deficits on tests of spatial working memory, object working memory, and set formation which are associated with hypometabolism in regions of prefrontal cortex (e.g., Andreasen et al., 1992; Berman et al., 1992; Park \& Holzman, 1992). Patients with the "positive" profile of schizophrenia have hallucinations as one of their primary symptoms. This symptom is associated with hypermetabolism in portions of the temporal lobe (Silberswieg et al., 1995). We propose that dysfunction of a single subcortical site, SNpr, could lead to all of these and related symptoms. At the very least, we believe that abnormal activity in nigral output channels participates in the symptoms associated with schizophrenia.

Examples of pallidal pathology lead to similar conclusions regarding its participation in a different set of neuropsychiatric symptoms. Patients with lesions largely localized to the globus pallidus display cognitive deficits, compulsive behaviors, and "psychic akinesia," in addition to varying degrees of skeletomotor symptoms (Laplane et al., 1989; Strub, 1989; Bhatia \& Marsden, 1994). It is generally accepted that alterations in pallidal output to motor areas of cortex account for the disturbances in motor function in these patients. It is just as likely that alterations in the pallidal output channels to prefrontal areas of cortex underlie the cognitive deficits, whereas alterations in potential pallidal channels to orbitofrontal and cingulate areas of cortex account for the compulsive symptoms (see Alexander et al., 1986; Cummings, 1993).

Overall, there is growing evidence that alterations in basal ganglia circuits with nonmotor areas of cortex occur in a wide variety of neuropsychiatric disorders, including not only schizophrenia and obsessive-compulsive disorder, but also depression, Tourette's syndrome, autism, and attention deficit disorder (e.g., Gaffney et al., 1989; Jernigan et al., 1991; Heckers et al., 1991; Anderson et al., 1992; Andreasen et al., 1992; Insel, 1992; Baxter, 1992; Berman et al., 1992; Breier et al., 1992; Buchsbaum et al., 1992; Liddle et al., 1992; Wise \& Rapoport, 1992; Swayze et al., 1992; Buchanan et al., 1993; Siegel et al., 1993; McGuire et al., 1994; Silberswieg et al., 1995; Robinson et al., 1995; Selemon et al., 1995; Schwartz et al., 1996; Arnold \& Trojanowski, 1996; Trivedi, 1996; Wolf et al., 1996; Casey et al., 1997; 
Filipek et al., 1997). It is possible that dysfunction of a specific set of output channels in the basal ganglia, and the cortical areas they innervate, is responsible for each unique set of symptoms in these disorders. Further experiments are needed to determine how many and which regions of the cerebral cortex participate in loops with the basal ganglia. We believe that defining these circuits will lead to important insights into the role of the basal ganglia in normal and abnormal cognitive function.

In conclusion, recent anatomical observations have challenged the view that basal ganglia output is solely concerned with motor control. It is now apparent that multiple cortical areas are the target of basal ganglia output, including not only the primary motor cortex, but also at least 9 other cortical areas, including subdivisions of premotor, oculomotor, prefrontal, and inferotemporal cortex. The basal ganglia output to individual cortical areas appears to originate from distinct clusters of neurons in the nigra or pallidum. This output is directed through specific regions of the thalamus to distinct cortical areas. We have termed the set of neurons in an individual basal ganglia output nucleus that projects to a given cortical area via the thalamus an 'output channel.' Physiological recordings in awake trained primates and functional imaging studies in humans suggest that individual output channels are involved in different functions that resemble the function of the cortical area they innervate. Clinical studies support these observations and suggest that dysfunction in individual basal ganglia loops with the cerebral cortex may underlie the development of specific neurological and psychiatric symptoms. Clearly, the basal ganglia influence on behavior is much more extensive than previously recognized.

\section{REFERENCES}

Alexander, G. E., DeLong, M. R., \& Strick, P. L. 1986. Parallel organization of functionally segregated circuits linking basal ganglia and cortex. Annual Review of Neuroscience, 9, $357-381$.

Anderson, G. M., Pollak, E. S., Chatterjee, D., Leckman, J. F., Riddle, M. A., \& Cohen, D. J. 1992. Postmortem analysis of subcortical monamines and amino acids in Tourette syndrome. Advances in Neurology, 58, 123-133.

Anderson, M. E., \& Horak, F. B. 1985. Influence of the globus pallidus on arm movements in monkeys. III. Timing of movement-related information. Journal of Neurophysiology, 54, 433-448.

Andreasen, N. C., Rezzai, K., Alliger, R., Swayze, V., Flaum, M., Kirchner, P., Cohen, G., \& O'Leary, D. S. 1992. Hypofrontality in neuroleptic-naive patients and in patients with chronic schizophrenia. Archives of General Psychiatry, 49, 943-958.

Arnold, S. E., \& Trojanowski, J. Q. 1996. Recent advances in defining the neuropathology of schizophrenia. Acta Neuropathologica, 92, 217-231.

Bakay, R. A., DeLong, M. R., \& Vitek, J. L. 1992. Posteroventral pallidotomy for Parkinson's disease. Journal of Neurosurgery, 77, 487-488.

Baker, S. C., Rogers, R. D., Owen, A. M., Frith, C. D., Dolan, R. J., Frackowiak, R. S., \& 
Robbins, T. W. 1996. Neural systems engaged by planning: A PET study of the Tower of London task. Neuropsychologia, 34, 515-526.

Baron, M. S., Vitek, J. L., Bakay, R. A., Green, J., Kaneoke, Y., Hashimoto, T., Turner, R. S., Woodard, J. L., Cole, S. A., McDonald, W. M., \& DeLong, M. R. 1996. Treatment of advanced Parkinson's disease by posterior GPi pallidotomy: 1-year results of a pilot study. Annals of Neurology, 40, 355-366.

Baxter, L. R. 1992. Neuroimaging studies of obsessive compulsive disorder. In M. A. Jenike (Ed.), Psychiatric clinics of North America: Obsessional disorders. Philadelphia: Saunders. Pp. 871-884.

Berman, K. F., Torrey, E. F., Daniel, D. G., \& Weinberger, D. R. 1992. Regional cerebral blood flow in monozygotic twins discordant and concordant for schizophrenia. Archives of General Psychiatry, 49, 927-934.

Bhatia, K. P., \& Marsden, C. D. 1994. The behavioural and motor consequences of focal lesions of the basal ganglia in man. Brain, 117, 859-876.

Breier, A., Buchanan, R. W., Elkashef, A., Munson, R. C., Kirkpatrick, B., \& Gellad, F. 1992. Brain morphology and schizophrenia. A magnetic resonance imaging study of limbic, prefrontal cortex, and caudate structures. Archives of General Psychiatry, 49, 921-926.

Buchanan, R. W., Breier, A., Kirkpatrick, B., Elkashef, A., Munson, R. C., Gellad, F., \& Carpenter, W. T. 1993. Structural abnormalities in deficit and nondeficit schizophrenia. American Journal of Psychiatry, 150, 59-65.

Buchsbaum, M. S., Haier, R. J., Potkin, S. G., Neuchterlein, K., Bracha, H. S., Katz, M., Lohr, J., Wu, J., Lottenberg, S., Jerabeck, P. A., Trenary, M., Tafalla, R., Reynolds, C., \& Bunney, W. E. 1992. Frontostriatal disorder of cerebral metabolism in never-medicated schizophrenics. Archives of General Psychiatry, 49, 935-942.

Butters, N., Sax, D., Montgomery, K., \& Tarlow, S. 1978. Comparison of the neuropsychological deficits associated with early and advanced Huntington's disease. Archives of Neurology, 35, 585-589.

Carlsson, M., \& Carlsson, A. 1990. Interactions between glutamatergic and monaminergic systems within the basal ganglia-Implications for schizophrenia and Parkinson's disease. Trends in Neuroscience, 13, 272-276.

Casey, B. J., Castellanos, F. X., Giedd, J. N., Marsh, W. L., Hamburger, S. D., Schubert, A. B., Vauss, Y. C., Vaituzis, A. C., Dickstein, D. P., Sarfatti, S. E., \& Rapoport, J. L. 1997. Implication of right frontostriatal circuitry in response inhibition and attentiondeficit/hyperactivity disorder. Journal of the American Academy of Child and Adolescent Psychiatry, 36, 374-383.

Castellanos, F. X., Giedd, J. N., Marsh, W. L., Hamburger, S. D., Vaituzis, A. C., Dickstein, D. P., Sarfatti, S. E., Vauss, Y. C., Snell, J. W., Lange, N., Kaysen, D., Krain, A. L., Ritchie, G. F., Rajapakse, J. C., \& Rapoport, J. L. 1996. Quantitative brain magnetic resonance imaging in attention-deficit hyperactivity disorder. Archives of General Psychiatry, 53, 607-616.

Csernansky, J. G., Murphy, G. M., \& Faustman, W. O. 1991. Limbic/mesolimbic connections and the pathogenesis of schizophrenia. Biological Psychiatry, 30, 383-400.

Cummings, J. L. 1993. Frontal-subcortical circuits and human behavior. Archives of Neurology, 50, 873-880.

DeLong, M. R. 1971. Activity of pallidal neurons during movement. Journal of Neurophysiology, 34, 414-427.

DeLong, M. R., Crutcher, M. D., \& Georgopoulos, A. P. 1983. Relations between movement and single cell discharge in the substantia nigra of the behaving monkey. Journal of Neuroscience, 3, 1599-1606. 
Divac, I., Rosvold, H. E., \& Swarcbart, M. K. 1967. Behavioral effects of selective ablation of the caudate nucleus. Journal of Comparative and Physiological Psychology, 63, 184190.

Dubois, B., \& Pillon, B. 1997. Cognitive deficits in Parkinson's disease. Journal of Neurology, 244, $2-8$.

Early, T. S., Reiman, E. M., Raichle, M. E., \& Spitznagel, E. L. 1987. Left globus pallidus abnormality in never-medicated patients with schizophrenia. Proceedings of the National Academy of Sciences USA, 84, 561-563.

Farina, E., Cappa, S. F., Polimeni, M., Magni, E., Canesi, M., Zecchinelli, A., Scarlato, G., \& Mariani, C. 1994. Frontal dysfunction in early Parkinson's disease. Acta Neurologica Scandinavica, 90, 34-38.

Funahashi, S., Bruce, C. J., \& Goldman-Rakic P. S. 1989. Mnemonic coding of visual space in the monkey's dorsolateral prefrontal cortex. Journal of Neurophysiology, 61, 331349.

Funahashi, S., Inoue, M., \& Kubota, K. 1997. Delay-period activity in the primate prefrontal cortex encoding multiple spatial positions and their order of presentation. Behavioral Brain Research, 84, 203-223.

Fuster, J. M. 1997. The prefrontal cortex. New York: Raven Press.

Fuster, J. M., \& Alexander, G. E. 1971. Neuron activity related to short-term memory. Science, 173, 652-654.

Fuster, J. M., Bauer, R. H., \& Jervey, J. P. 1982. Cellular discharge in the dorsolateral prefrontal cortex of the monkey in cognitive tasks. Experimental Neurology, 77, 679-694.

Gaffney, G. R., Kuperman, S., Tsai, L. Y., \& Minchin, S. 1989. Forebrain structure in infantile autism. Journal of the American Academy of Child and Adolescent Psychiatry, 8, 534537.

Goldman, P. S., \& Rosvold, H. E. 1970. Localization of function within the dorsolateral prefrontal cortex of the rhesus monkey. Experimental Neurology, 27, 291-304.

Goldman-Rakic, P. S. 1987. Circuitry of primate prefrontal cortex and regulation of behavior by representational memory. In F. Plum (Ed.) Handbook of physiology, Section 1. The nervous system. Vol V. Bethesda: Am Physiol Soc. Pp. 373-413.

Goldman-Rakic, P. S. 1990. Cellular and circuit basis of working memory in prefrontal cortex of nonhuman primates. In H. B. M. Uylings, C. G. Van Eden, J. P. C. DeBruin, M. A. Corner, \& M. G. P. Feenstra (Eds.), Progress in brain research. New York: Elsevier Science. Pp. 325-336.

Gross, C. G. 1972. Visual functions of inferotemporal cortex. In: R. Jung (Ed.) Handbook of sensory physiology. Berlin: Springer-Verlag. Pp. 451-482.

Heckers, S., Heinsen, H., Heinsen, Y., \& Beckman, H. 1991. Cortex, white matter, and basal ganglia in schizophrenia: A volumetric post mortem study. Biological Psychiatry, 29, $556-566$.

Heindel, W. C., Salmon, D. P., Shults, C. W., Walicke, P. A., \& Butters, N. 1989. Neuropsychological evidence for multiple implicit memory systems: A comparison of Alzheimer's, Huntington's, and Parkinson's disease patients. Journal of Neuroscience, 9, 582-587.

Hikosaka, O., \& Wurtz, R. H. 1983. Visual and oculomotor functions of monkey substantia nigra pars reticulata. I. Relation of visual and auditory responses to saccades. Journal of Neurophysiology, 49, 1230-1253.

Hikosaka, O., Sakamoto, M., \& Miyashita, N. 1993. Effects of caudate nucleus stimulation on substantia nigra cell activity in monkey. Experimental Brain Research, 95, 457-472.

Hoover, J. E., \& Strick, P. L. 1993. Multiple output channels in the basal ganglia. Science, 259, 819-821. 
Hoover, J. E. \& Strick, P. L. 1999. The organization of cerebello- and pallido-thalamic projections to primary motor cortex: An investigation employing retrograde transneuronal transport of herpes simplex virus type 1. Journal of Neuroscience, 19, 1446-1463.

Hutton, S. B., Crawford, T. J., Puri, B. K., Duncan, L. J., Chapman, M., Kennard, C., Barnes, T. R., \& Joyce, E. M. 1998. Smooth pursuit and saccadic abnormalities in first-episode schizophrenia. Psychological Medicine, 28, 685-692.

Hutton, S., \& Kennard, C. 1998. Oculomotor abnormalities in schizophrenia: A critical review. Neurology, 50, 604-609.

Insel, T. R. 1992. Toward a neuroanatomy of obsessive-compulsive disorder. Archives of General Psychiatry, 49, 739-744.

Jernigan, T. L., Zisook, S., Heaton, R., Moranville, J. T., Hesselink, J. R., \& Braff, D. L. 1991. Magnetic resonance imaging abnormalities in lenticular nuclei and cerebral cortex in schizophrenia. Archives of General Psychiatry, 48, 881-890.

Jueptner, M., Frith, C. D., Brooks, D. J., Frackowiak, R. S., \& Passingham, R. E. 1997a. Anatomy of motor learning. II. Subcortical structures and learning by trial and error. Journal of Neurophysiology, 77, 1325-1337.

Jueptner, M., Stephan, K. M., Frith, C. D., Brooks, D. J., Frackowiak, R. S., \& Passingham, R. E. 1997b. Anatomy of motor learning. I. Frontal cortex and attention to action. Journal of Neurophysiology, 77, 1313-1324.

Kemp, J. M., \& Powell, T. P. S. 1971. The connexions of the striatum and globus pallidus: synthesis and speculation. Philosophical Transactions of the Royal Society of London, Series B: Biological Sciences, 262, 441-457.

Kish, S. J., Shannak, K., \& Hornykiewicz, O. 1988. Uneven pattern of dopamine loss in the striatum of patients with idiopathic Parkinson's disease. Pathophysiologic and clinical implications. New England Journal of Medicine, 318, 876-880.

Kubota, K., \& Niki, H. 1971. Prefrontal cortical unit activity and delayed alternation performance in monkeys. Journal of Neurophysiology, 34, 337-347.

Laplane, D., Levasseur, M., Pillon, B., Dubois, B., Baulac, M., Mazoyer, B., Tran Dinh, S., Sette, G., Danze, F., \& Baron, J. C. 1989. Obsessive-compulsive and other behavioural changes with bilateral basal ganglia lesions. Brain, 112, 699-725.

Lawrence, A. D., Sahakian, B. J., Hodges, J. R., Rosser, A. E., Lange, K. W., \& Robbins, T. W. 1996. Executive and mnemonic functions in early Huntington's disease. Brain, 119, 1633-1645.

Levin, B. E., Llabre, M. M., \& Weiner, W. J. 1989. Cognitive impairments associated with early Parkinson's disease. Neurology, 39, 557-561.

Liddle, P. F., Friston, K. J., Frith, C. D., Hirsch, S. R., Jones, T., \& Frackowiak, R. S. J. 1992. Patterns of cerebral blood flow in schizophrenia. British Journal of Psychiatry, 160, 179186.

Lynch, J. C., Hoover, J. E., \& Strick, P. L. 1994. Input to the primate frontal eye field from the substantia nigra, superior colliculus, and dentate nucleus demonstrated by transneuronal transport. Experimental Brain Research, 100, 181-186.

Martin, J. P. 1927. Hemichorea resulting from a local lesion of the brain (the syndrome of the body of Luys). Brain, 50, 637-651.

McGuire, P. K., Bench, C. J., Frith, C. D., Marks, I. M., Frackowiak, R. S., \& Dolan, R. J. 1994. Functional anatomy of obsessive-compulsive phenomena. British Journal of Psychiatry, 164, 459-468.

McKee, A. C., Levine, D. N., Kowall, N. W., \& Richardson, E. P. 1990. Peduncular hallucinosis associated with isolated infarction of the substantia nigra pars reticulata. Annals of Neurology, 27, 500-504. 
Middleton, F. A., \& Strick, P. L. 1994. Anatomical evidence for cerebellar and basal ganglia involvement in higher cognitive function. Science, 266, 458-461.

Middleton, F. A., \& Strick, P. L. 1996. The temporal lobe is a target of output from the basal ganglia. Proceedings of the National Academy of Sciences USA, 93, 8683-8687.

Middleton, F. A., \& Strick, P. L. 1997a. New concepts about the organization of basal ganglia output. Advances in Neurology, 74, 57-68.

Middleton, F. A., \& Strick, P. L. 1997b. Dentate output channels: Motor and cognitive components. Progress in Brain Research, 114, 555-568.

Mink, J. W. \& Thach, W. T. 1991. Basal ganglia motor control: I. Nonexclusive relation of pallidal discharge to five movement modes. Journal of Neurophysiology, 65, 273-300.

Miyachi, S., Hikosaka, O., Miyashita, K., Karadi, Z., \& Rand, M. K. 1997. Differential roles of monkey striatum in learning of sequential hand movement. Experimental Brain Research, 115, 1-5.

Miyashita, Y. 1993. Inferior temporal cortex: Where visual perception meets memory. Annual Review of Neuroscience, 16, 245-263.

Modell, J. G., Mountz, J. M., Curtis, G. C., \& Greden, J. F. 1989. Neurophysiologic dysfunction in basal ganglia/limbic striatal and thalamocortical circuits as a pathogenetic mechanism of obsessive-compulsive disorder. Journal of Neuropsychiatry and Clinical Neurosciences, 1, 27-36.

Mushiake, H., \& Strick, P. L. 1993. Preferential activity of dentate neurons during limb movements guided by vision. Journal of Neurophysiology, 70, 2660-2664.

Mushiake, H., \& Strick, P. L. 1995a. Pallidal neuron activity during sequential arm movements. Journal of Neurophysiology, 74, 2754-2758.

Mushiake, H., \& Strick, P.L. 1995b. Cerebellar and pallidal activity during instructed delay periods. Society for Neuroscience Abstracts, 21, 411.

Niki, H., \& Watanabe, M. 1976. Prefrontal unit activity and delayed response: Relation to cue location versus direction of response. Brain Research, 105, 79-88.

Olszewski, J. 1952. The thalamus of Macaca mulatta. An atlas for use with the stereotaxic instrument. Basel: Karger.

Owen, A. M. 1997. Cognitive planning in humans: Neuropsychological, neuroanatomical and neuropharmacological perspectives. Progress in Neurobiology, 53, 431-450.

Owen, A. M., Beksinska, M., James, M., Leigh, P. N., Summers, B. A., Marsden C. D., Sahakian B. J., \& Robbins T. W. 1993. Visuospatial memory deficits at different stages of Parkinson's disease. Neuropsychologia, 31, 627-644.

Owen, A. M., Doyon, J., Dagher, A., Sadikot, A., \& Evans, A. C. 1998. Abnormal basal ganglia outflow in Parkinson's disease identified with PET. Implications for higher cortical functions. Brain, 121, 949-965

Owen, A. M., Doyon, J., Petrides, M., \& Evans, A. C. 1996. Planning and spatial working memory: A positron emission tomography study in humans. European Journal of Neuroscience, 8, 353-364.

Owen, A. M., James, M., Leigh, P. N., Summers, B. A., Marsden, C. D., Quinn, N. P., Lange, K. W. \& Robbins, T. W. 1992. Fronto-striatal cognitive deficits at different stages of Parkinson's disease. Brain, 115, 1727-1751.

Palfi, S., Ferrante, R. J., Brouillet, E., Beal, M. F., Dolan, R., Guyot, M. C., Peschanski, M. \& Hantraye, P. 1996. Chronic 3-nitropropionic acid treatment in baboons replicates the cognitive and motor deficits of Huntington's disease. Journal of Neuroscience, 16, 3019-3025.

Park, S., \& Holzman, P. S. 1992. Schizophrenics show spatial working memory deficits. Archives of General Psychiatry, 49, 975-982. 
Partiot, A., Verin, M., Pillon, B., Teixeira-Ferreira, C., Agid, Y., \& Dubois, B. 1996. Delayed response tasks in basal ganglia lesions in man: Further evidence for a striato-frontal cooperation in behavioural adaptation. Neuropsychologia, 34, 709-721.

Pascual-Leone, A., Grafman, J., Clark, K., Stewart, M., Massaquoi, S., Lou, J. S., \& Hallett, M. 1993. Procedural learning in Parkinson's disease and cerebellar degeneration. Annals of Neurology, 34, 594-602.

Robinson, D., Wu, H., Munne, R. A., Ashtari, M., Alvir, J. M., Lerner, G., Koreen, A., Cole, K., \& Bogerts, B. 1995. Reduced caudate nucleus volume in obsessive-compulsive disorder. Archives of General Psychiatry, 52, 393-398.

Roeltgen, D. P., \& Schneider, J. S. 1994. Task persistence and learning ability in normal and chronic low dose MPTP-treated monkeys. Behavioral Brain Research, 60, 115-124.

Saint-Cyr, J. A., Taylor, A. E., \& Lang, A. E. 1988. Procedural learning and neostriatal dysfunction in man. Brain, 111, 941-959.

Schneider, J. S., \& Pope-Coleman, A. 1995. Cognitive deficits precede motor deficits in a slowly progressing model of parkinsonism in the monkey. Neurodegeneration, 4, 245255.

Schneider, J. S., \& Roeltgen, D. P. 1993. Delayed matching-to-sample, object retrieval, and discrimination reversal deficits in chronic low dose MPTP-treated monkeys. Brain Research, 615, 351-354.

Schultz, W. 1986. Activity of pars reticulata neurons of monkey substantia nigra in relation to motor, sensory, and complex events. Journal of Neurophysiology, 55, 660-677.

Schwartz, J. M., Stoessel, P. W., Baxter, L. R., Jr., Martin, K. M., \& Phelps, M. E. 1996. Systematic changes in cerebral glucose metabolic rate after successful behavior modification treatment of obsessive-compulsive disorder. Archives of General Psychiatry, 53, 109-113.

Siegel, B. V., Buchsbaum, M. S., Bunney, W. E., Gottschalk, L. A., Haier, J., Lohr, J. B., Lottenberg, S., Najafi, A., Neuchterlein, K. H., Potkin, S. G., \& Wu, J. C. 1993. Corticalstriatal-thalamic circuits and brain glucose metabolic activity in 70 unmedicated male schizophrenic patients. American Journal of Psychiatry, 150, 1325-1336.

Silbersweig, D. A., Stern, E., Frith, C., Cahill, C., Holmes, A., Grootoonk, S., Seaward, J., McKenna, P., Chua, S. E., Schnorr, L., Jones, T., \& Frackowiak, R. S. J. 1995. A functional neuroanatomy of hallucinations in schizophrenia. Nature, 378, 176-179.

Strick, P. L., \& Card, J. P. 1992. Transneuronal mapping of neural circuits with alpha herpesviruses. In J.P. Bolam (Ed.), Experimental neuroanatomy: A practical approach. Oxford: Oxford Univ. Press. Pp. 81-101.

Strick, P. L., Dum, R. P., \& Mushiake, H. 1995. Basal ganglia 'loops' with the cerebral cortex. In M. Kimura \& A.M. Graybiel (Eds.), Functions of the cortico-basal ganglia loop. Tokyo: Springer-Verlag. Pp. 106-124.

Strick, P. L., Hoover, J. E., \& Mushiake, H. 1993. Evidence for "output channels"' in the basal ganglia and cerebellum. In N. Mano, I. Hamada, \& M.R. DeLong (Eds.), Role of the cerebellum and basal ganglia in voluntary movement. Amsterdam: Elsevier. Pp. 171180.

Strub, R. L. 1989. Frontal lobe syndrome in a patient with bilateral globus pallidus lesions. Archives of Neurology, 46, 1024-1027.

Swayze, V. W., Andreasen, N. C., Alliger, R. J., Yuh, W. T., \& Ehrhardt, J. C. 1992. Subcortical and temporal structures in affective disorder and schizophrenia: A magnetic resonance imaging study. Biological Psychiatry, 31, 221-240.

Swedo, S. E., Schapiro, M. B., Grady, C. L., Cheslow, D. L., Leonard, H. L., Kumar, A., Friedland, R., Rapoport, S.I., \& Rapoport, J. L. 1989. Cerebral glucose metabolism in 
childhood-onset obsessive-compulsive disorder. Archives of General Psychiatry, 46, 518-523.

Swerdlow, N. R., \& Koob, G. F. 1987. Dopamine, schizophrenia, mania, and depression: Toward a unified hypothesis of cortico-striato-pallido-thalamic function. Behavioral Brain Science, 10, 197-245.

Tanaka, K., Saito, H.-A., Fukuda, Y., \& Moriya, M. 1991. Coding visual images of objects in the inferotemporal cortex of the macaque monkey. Journal of Neurophysiology, 66, 170-189.

Taylor, A. E., Saint-Cyr, J. A., \& Lang, A. E. 1990. Memory and learning in early Parkinson's disease: Evidence for a "frontal lobe syndrome." Brain and Cognition, 13, 211-232.

Trepanier, L. L., Saint-Cyr, J. A., Lozano, A. M., \& Lang, A. E. 1998. Neuropsychological consequences of posteroventral pallidotomy for the treatment of Parkinson's disease. Neurology, 51, 207-215

Trivedi, M. H. 1996. Functional neuroanatomy of obsessive-compulsive disorder. Journal of Clinical Psychiatry, 57, 26-36.

vonSattel, J. P., Myers, R. H., Stevens, T. J., Ferrante, R. J., Bird, E. D., \& Richardson, E.P. 1985. Neuropathological classification of Huntington's disease. Journal of Neuropathology and Experimental Neurology, 44, 559-577.

Walker, E. F. 1994. Developmentally moderated expressions of the neuropathology underlying schizophrenia. Schizophrenia Bulletin, 20, 453-480.

Wilson, S. A. K. 1912. Progressive lenticular degeneration. Brain, 34, 295-509.

Wise, S. P., \& Rapoport, J. L. 1992. Obsessive-compulsive disorder: Is it basal ganglia dysfunction. In J.L. Rapoport (Ed.) Obsessive compulsive disorder in children and adolescents. Washington, DC: Am. Psychiat. Press. Pp. 327-344.

Wolf, S. S., Jones, D. W., Knable, M. B., Gorey, J. G., Lee, K. S., Hyde, T. M., Coppola, R., \& Weinberger, D. R. 1996. Tourette syndrome: Prediction of phenotypic variation in monozygotic twins by caudate nucleus D2 receptor binding. Science, 273, 1225-1227.

Zemanick, M. C., Strick, P. L., \& Dix, R. D. 1991. Transneuronal transport of herpes simplex virus type 1 in the primate motor system: Transport direction is strain dependent. Proceedings of the National Academy of Sciences USA, 88, 8048-8051. 